\title{
Evaluating the Effect of Chronotype on Meal Timing and Obesity in Iranian Housewives: A Cross-Sectional Study
}

\author{
Amirhossein Yazdinezhad $^{1(D)}$, Moslem Askarpour ${ }^{10}$, Mohammad Mehdi Aboushamsia' (iD), \\ Maryam Asadi ${ }^{1,2}$ (D), Anahita Mansoori ${ }^{2+}$ (iD
}

1. Student Research Committee. Ahvaz, Jundishapur University of Medical Sciences, Ahvaz, Iran.

2. Nutrition and Metabolic Diseases Research Center, Ahvaz Jundishapur University of Medical Sciences, Ahvaz, Iran

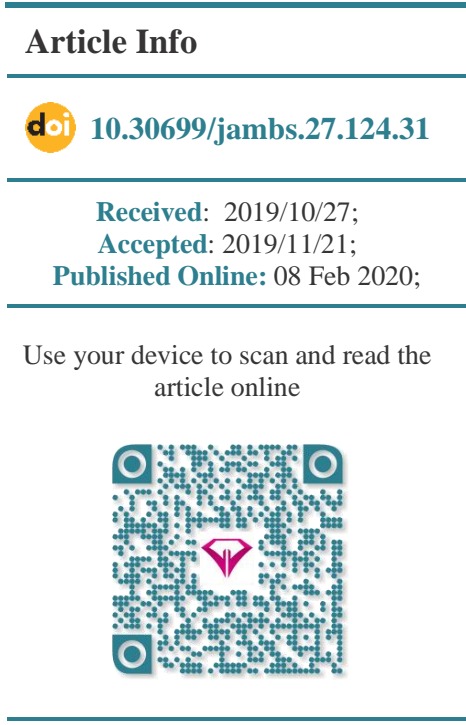

Corresponding Information:

Anahita Mansoori, Nutrition and Metabolic Diseases Research Center. Jundishapur University of Medical Sciences, Ahvaz, Khuzestan, Iran.

Email:

Mansoori_anahita@yahoo.com

Mansoori-a@ajums.ac.ir

\section{ABSTRACT}

Background \& Objective: Recent studies have shown a relationship between energy regulation and the circadian rhythm at behavioral, molecular, and physiological levels. The present study investigated the effect of chronotype on meal timing and obesity in Iranian housewives.

Materials \& Methods: This cross-sectional study was carried out using a convenience-sampling method through the participation of housewives living in Ahvaz in 2018. Anthropometric information was collected. To assess food intake timing, energy intake and sleep patterns during seven days of normal living were recorded by the researchers. Dietary information was obtained by using a 24-hour recall questionnaire and analyzed by NUT IV software. The morningness-eveningness questionnaire (MEQ) was used to determine chronotypes.

Results: There was a significant difference between the morning and evening groups in terms of the timing of lunch $(P=0.004)$ and mid-afternoon snacks $(P=0.04)$. There was no significant difference between mean energy intake in the morning and evening chronotypes in women who were overweight or obese $(P=0.31)$. There was also no significant difference between morning and evening chronotypes in terms of the percentage of energy intake of meals and snacks $(P>0.05)$. The only significant difference, detected between morning and evening chronotypes in normal-weight women, was for the percentage of energy intake after 3:00 PM. $(P=0.008)$.

Conclusion: The present study showed no effect of chronotype on obesity. However, energy intake calculations were based on self-reports, which could lead to information bias. Therefore, in future studies, researchers should carry out clinical trials while controlling food intake and considering meal timing.

Keywords: Chronotype, Energy regulation, Obesity, Meal timing, Sleep patterns

\section{Introduction}

Obesity and being overweight are risk factors for cardiovascular diseases and hypertension (1). According to various studies, obesity and being overweight are associated with diabetes, myocardial infarction, lipid disorders, hypertension, dyslipidemia, sleep apnea, gallbladder diseases, coronary artery disease, gout, and cancer $(2,3)$. Obesity reduces one's chances of survival, as well as their life expectancy. Obesity and being overweight are highly prevalent in countries located in the Persian Gulf region, especially among women-it is estimated that between $75 \%$ and $88 \%$ of this population are overweight or obese (4). The situation has worsened in Iran in recent years. In this regard, the results of a study showed that $63.9 \%$ of Iranian women are either overweight or obese. Although the current strategies for reducing obesity are focused on the imbalance between calorie intake and energy expenditure, recent studies have shown that there is a relationship between energy regulation and the circadian rhythm at behavioral, molecular, and physiological levels (5-8). Some studies also emphasized that eating hours might play a significant role in weight adjustment (9).

A study reported that evening-type subjects had higher weight and body mass index (BMI) than morning-type subjects (10). However, other studies reported no significant relationship between morningness/eveningness and BMI $(\mathbf{1 1}, 12)$. Thus, the results of previous studies are controversial. Considering that there are few related studies on this topic and that this issue can be considered as a determinant of the obesity risk in our country, the present study aimed to investigate the effect of chronotype on meal timing and obesity in Iranian housewives. 


\section{Materials and Methods}

\section{Participants}

This cross-sectional study was written according to the strengthening the reporting of observational studies in epidemiology (STROBE) checklist (13). This study was conducted by using the simple sampling method (computer-generated random numbers) to decrease the probable bias. Announcements were used to invite eligible subjects (housewives) for participation, living in Ahvaz, Iran. Relevant information was collected after obtaining written consent. Individuals were included in the study if they were literate and aged over 20 years, as well as willing to maintain weight and physical activity during the study period. Pregnancy, breastfeeding, being on a weight loss and weight gain diet in the past six months, suffering from certain diseases that affect individuals' diet (such as cardiovascular diseases and eating disorders), taking medications that can affect appetite or weight (including fluoxetine, sulfasalazine, and topiramate), thyroid disorders, and smoking were considered as an exclusion criteria. This study was funded by Ahvaz Jundishapur University of Medical Sciences. The study protocol was approved by the ethics committee based on the ethical guidelines of the 2013 Declaration of Helsinki at Ahvaz Jundishapur University of Medical Sciences. (Ethics code: 1396.1029 IR.AJUMS.REC).

\section{Methods of Data Collection}

The following anthropometric information was collected: height measurement by using a tape measure with accuracy of $0.1 \mathrm{~cm}$ (in a standing position, wearing no shoes, and with shoulders kept in a normal position); weight measurement by using the Omron BF508 scale with a precision of $100 \mathrm{~g}$ (without shoes and with minimal clothes), BMI (weight in kilograms divided by the square of height in meters); and waist circumference in the narrowest region between the last rib and the upper part of the flat pelvic region at the end of a normal exhalation by using a non-elastic tape measure without imposing any pressure on the body.

Individuals with a BMI of $\geq 25$ were considered as being overweight or obese, and those with a BMI of 18.5-24.9 were considered normal-weight subjects.

To assess the timing of food intake, a notepad was given to each participant so that they could record the types of eaten food, time at which they ate, and sleep pattern, as well as how the meal was prepared and the amount of food eaten during seven days of normal living. Individuals were given verbal and written instructions on how to record food intake. To determine the chronotype (circadian rhythm), the morningness-eveningness questionnaire (MEQ) was used. A person's chronotype represents their waking and sleeping pattern. Some people naturally sleep late and wake up late in the morning (eveningness), while other people go to bed early and wake up early in the morning (morningness).
The chronotype questionnaire was developed by Horn and Sternberg in 1976 and consists of 19 questions divided into the three sections of an awakening preference (seven questions), sleep preference (six questions), and optimal performance preference (six questions) (14). The questionnaire's options are not equal in value, and according to the developers' analysis, different values are given to the options for each question. Mozafari et al. confirmed the validity of the questionnaire in their study in Iran and reported a Cronbach's alpha of 0.71 (15). The possible score range is 16 to 86 with high and low scores, indicating morningness and eveningness preferences, respectively.

In the present study, people's chronotypes were calculated based on their MEQ scores. The subjects were divided into two groups: low scores (evening group; 16-51 points) and high scores (morning group; 52-86 points) (14). To measure the physical activity level, a physical activity questionnaire was used and completed by the interview method, and the results were expressed as metabolic equivalents (MET-h/day). Dietary intake was assessed by using a 24-hour recall questionnaire. Calorie and macronutrient intakes were analyzed by Nutritionist IV software (Hearst Corporation, San Bruno, CA, USA).

\section{Statistical Analysis}

The normal distribution of variables was assessed via the Kolmogorov-Smirnov test. In the case of the nonnormal data distribution, the normal distribution was obtained by calculating the logarithm, otherwise, a Chi-square test was used to compare variables between groups. An independent sample T-test was used to compare the variables with the normal distribution between groups. Also, an independent sample T-test was used in this study to compare different times, including the sleep onset, end of sleep, sleep duration, duration of main meals and snacks, interval between the last snack, and sleep between morning and evening chronotypes (Table 2). The percentage of the total calorie intake, calorie intake in the main meals, and calorie intake before and after 3:00 PM were calculated, and these values were compared between morning and evening chronotype of normal weight and overweight/obesity subjects via independent sample Ttest (Table 3). Statistical analysis was carried out by using SPSS version 25 (SPSS Inc., Chicago, IL., USA). software, and P-value $<0.05$ was considered as a significant level.

\section{Results}

\section{Description of the Studied Population}

Ninety-six women participated in the present study. Table 1 shows the characteristics of the participants based on their chronotype. There was a significant difference between the morning and evening groups in terms of the timing of lunch $(P=0.004)$, and midafternoon snack $(P=0.04)$. However, no significant 
difference was observed in the rest of the meal timings (Table 2).

\section{Food Intake Timing}

The mean energy intake in morning and evening chronotypes in women with normal weight was $1446 \pm$ 352 and $1373 \pm 225 \mathrm{kcal} /$ day, respectively, which was not statistically significant $(P=0.46)$. Also, there was no significant difference between mean energy intake in the morning and evening chronotypes in women with overweight or obesity $(P=0.31)$ (Table 3$)$. There was also no significant difference between morning and evening chronotypes of women with normal weight regarding the percentage of energy intake at breakfast meal $(P<0.31)$, as well as in women with obesity or overweight $(P=0.72)$. In addition, there was no significant difference between morning and evening chronotypes in the percentage of energy intake in lunch, dinner, and snack meals (Table 3). The percentage of energy intake was measured between chronotype groups before and after 3:00 PM, and results reported no significant difference before 3:0 PM. However, there was a significant difference between morning and evening chronotypes in normalweight women for the percentage of energy intake after 3:00 PM The percentage of calorie intake in the evening group was higher than the morning group $(P=$ $0.008)$. However, there was no significant difference between women with overweight and obesity in this regard $(P=0.36)$ (Table 3).

Table 1. Characteristics of the participants based on their chronotype.

\begin{tabular}{|c|c|c|c|c|c|c|}
\hline & \multicolumn{3}{|c|}{ Normal weight } & \multicolumn{3}{|c|}{ Overweight/obesity } \\
\hline & $\begin{array}{l}\text { Morning } \\
(\mathrm{n}=25)\end{array}$ & $\begin{array}{l}\text { Evening } \\
(\mathrm{n}=16)\end{array}$ & $\begin{array}{c}\mathrm{P}- \\
\text { value }\end{array}$ & $\begin{array}{l}\text { Morning } \\
(\mathrm{n}=39)\end{array}$ & $\begin{array}{l}\text { Evening } \\
(\mathrm{n}=16)\end{array}$ & $\begin{array}{l}{ }^{*} \mathrm{P}- \\
\text { value }\end{array}$ \\
\hline Age(Years) & $30.6 \pm 10.6$ & $31.7 \pm 8.2$ & 0.71 & $30.8 \pm 8.7$ & $33.0 \pm 9.8$ & 0.43 \\
\hline $\mathrm{BMI}\left(\mathrm{Kg} / \mathrm{m}^{2}\right)$ & $22.3 \pm 1.9$ & $21.5 \pm 2.0$ & 0.91 & $29.5 \pm 3.9$ & $30.7 \pm 4.0$ & 0.32 \\
\hline $\mathrm{WC}(\mathrm{cm})$ & $79.2 \pm 4.0$ & $78.8 \pm 6.1$ & 0.81 & $94.1 \pm 11.4$ & $95.0 \pm 8.6$ & 0.78 \\
\hline $\begin{array}{l}\text { Physical activity } \\
\text { (MET/day) }\end{array}$ & $38.5 \pm 3.5$ & $39.6 \pm 5.4$ & 0.42 & $40.6 \pm 5.6$ & $39.8 \pm 7.3$ & 0.68 \\
\hline
\end{tabular}

BMI, body mass index; WC, waist circumference.

Data are expressed as means \pm standard deviation.

*P-values were obtained from independent samples t-test.

Table 2. Comparison of sleep and meal timings between morning and evening chronotypes.

\begin{tabular}{|c|c|c|c|}
\hline & Morning type $(n=64)$ & Evening type $(n=32)$ & *P-value \\
\hline Sleep start (hh) & $22.6 \pm 3.4$ & $23.5 \pm 42$ & 0.16 \\
\hline Sleep end (hh) & $7.3 \pm 1.1$ & $8.1 \pm 1.1$ & 0.17 \\
\hline Sleep duration (hours) & $8.6 \pm 1.0$ & $8.8 \pm 0.9$ & 0.79 \\
\hline Breakfast time (hh) & $8.1 \pm 0.8$ & $8.7 \pm 0.9$ & 0.19 \\
\hline Mid-morning snack time (hh) & $10.8 \pm 0.9$ & $10.7 \pm 2.1$ & 0.17 \\
\hline Lunch time (hh) & $13.2 \pm 0.7$ & $13.9 \pm 0.8$ & 0.004 \\
\hline Mid-afternoon snack time (hh) & $17.3 \pm 1.3$ & $17.9 \pm 1.0$ & 0.04 \\
\hline Dinner time (hh) & $20.8 \pm 1.0$ & $21.0 \pm 1.0$ & 0.46 \\
\hline After dinner snack time (hh) & $21.9 \pm 0.9$ & $22.4 \pm 0.9$ & 0.13 \\
\hline Last meal-sleep onset (hours) & $5.9 \pm 1.6$ & $5.8 \pm 1.8$ & 0.19 \\
\hline
\end{tabular}

Data are expressed as means \pm standard deviation.

${ }^{*} \mathrm{P}$-values were obtained from independent samples t-test. 
Table 3. Comparison of total calorie intake and meal timing in the morning and evening chronotypes.

\begin{tabular}{ccccccc} 
& \multicolumn{2}{c}{ Normal weight } & & \multicolumn{2}{c}{ Overweight/obesity } \\
\hline & $\begin{array}{c}\text { Morning type } \\
(\mathrm{n}=25)\end{array}$ & $\begin{array}{c}\text { Evening type } \\
(\mathrm{n}=16)\end{array}$ & $\begin{array}{c}\mathrm{P}- \\
\text { value }\end{array}$ & $\begin{array}{c}\text { Morning type } \\
(\mathrm{n}=39)\end{array}$ & $\begin{array}{c}\text { Evening type } \\
(\mathrm{n}=16)\end{array}$ & $\begin{array}{c}{ }^{*} \mathrm{P}- \\
\text { value }\end{array}$ \\
$\begin{array}{c}\text { Total energy (Kcal, } \\
\text { mean } \pm \text { SD) }\end{array}$ & $1446 \pm 352$ & $1373 \pm 225$ & $0.46^{\mathrm{a}}$ & $1567 \pm 380$ & $1453 \pm 350$ & $0.31^{\mathrm{a}}$ \\
$\begin{array}{c}\text { \% Breakfast } \\
\text { \% Lunch }\end{array}$ & $19.8 \pm 5.8$ & $17.9 \pm 5.4$ & $0.31^{\mathrm{b}}$ & $19.7 \pm 6.8$ & $20.4 \pm 4.2$ & $0.72^{\mathrm{b}}$ \\
$\begin{array}{c}\text { \% Dinner } \\
\text { \% Calories from } \\
\text { Snack }\end{array}$ & $35.6 \pm 11.0$ & $34.9 \pm 5.6$ & $0.79^{\mathrm{b}}$ & $35.9 \pm 6.1$ & $35.9 \pm 6.0$ & $0.98^{\mathrm{b}}$ \\
\hline $\begin{array}{c}\text { \% Calories before 3 } \\
\text { PM }\end{array}$ & $22.3 \pm 7.1$ & $25.4 \pm 8.6$ & $0.21^{\mathrm{b}}$ & $25.2 \pm 6.1$ & $22.8 \pm 5.2$ & $0.18^{\mathrm{b}}$ \\
\hline $\begin{array}{c}\text { \% Calories after 3 } \\
\text { PM }\end{array}$ & $60.5 \pm 12.8$ & $52.5 \pm 12.1$ & $0.056^{\mathrm{b}}$ & $60.9 \pm 10.2$ & $59.6 \pm 9.4$ & $0.67^{\mathrm{b}}$ \\
\hline
\end{tabular}

*P-values were obtained from independent samples t-test.

${ }^{\text {a }}$ Independent sample T-test.

${ }^{\mathrm{b}}$ Chi-square test.

\section{Discussion}

The present study indicated that the time of eating lunch and mid-afternoon snack in the evening group is significantly later than in the morning group. Also, regarding normal-weight women, the percentage of energy intake after 3:00 PM. is significantly higher in individuals with an evening chronotype than those with a morning chronotype. However, in general, this difference in food intake timing and energy intake percentage at certain hours did not make any difference in terms of total daily energy intake and BMI.

Obesity and overweight statuses are highly prevalent in different regions of Iran. A review in Iran reported that $21 \%$ of people over the age of 18 are obese (16).

An animal study reported that mice that received high-fat diets just at the right time (for example, at night) had gained significantly less weight than mice that ate the same food at an inappropriate time (9). In addition, human studies reported similar results (1719). However, Muñoz et al. reported that there was no relationship between weight gain and eating dinner after 8:00 PM (17). Another study displayed that having breakfast is not associated with obesity, but those who receive more than $33 \%$ of their daily energy intake in the evening are twice as likely to suffer from obesity than those who do not (20). Also, large energy intake at breakfast can help reduce overall intake, while a lot of energy intake at night can result in increasing overall food intake (21).

Also, some studies have shown that many biological processes, such as the sleep-wake or food intake cycles, are rhythmically regulated in humans (22). Circadian rhythms are biological processes that oscillate over approximately 24 hours and are produced in the suprachiasmatic nucleus of the hypothalamus (23).
Some regulators control the rhythms that are produced by the suprachiasmatic nucleus. The main regulator is light (24).

Biological clocks have been understood since 2001 . In addition to the central clock that is located in the suprachiasmatic nucleus, other biological clocks are located in different parts of the body, such as the heart, liver, pancreas, and adipose tissue (25). Also, biological clocks other than the central clock have been found in parts of the brain, such as the mediobasal hypothalamus and olfactory bulb.

These biological clocks are coordinated by the brain but can become uncontrollable based on factors such as the time of eating (26). Thus, eating at an inappropriate time can cause disturbances in circadian rhythms by inducing the internal asynchrony between biological clocks and the central suprachiasmatic nucleus (27). This physiological change can cause a variety of disorders, such as obesity (28).

One of the newest discoveries in this field is the presence of an active circadian clock in adipose tissue (29). Recent data indicate that a temporal element is involved in the regulation of the functioning of adipose tissue (30). In fact, some studies have shown that a significant percentage of the expression of a gene in the adipose tissue of humans and animals follows a rhythmic pattern $(31,32)$. Therefore, specific time order in the daily pattern of these genes should be very important because the adipose tissue can cause fat accumulation or fat movement at one particular time (33).

Ross et al. and Ruiz-Lozano et al. calculated MEQ scores to investigate the relationship between chronotype and BMI and reported that eveningness 
subjects had a higher weight and BMI than morningness subjects $(\mathbf{1 0 , 3 4 )}$. This result is not in line with our results. This discrepancy might be due to the differences in the sample size and study design. Other researchers have reported that there is no significant relationship between the MEQ scores and BMI of morningness and eveningness subjects, which is in line with our results $(11,35)$.

There is some evidence that genetics affects one's chronotype. One investigator observed that there is an interaction between clock gene polymorphism and chronotype for obesity measurements, such as weight, BMI, and waist circumference. Among carriers of the allele $\mathrm{C}$ in clock $3111 \mathrm{~T} / \mathrm{C}$, eveningness subjects were heavier than morningness subjects (34).

Although we considered many confounding variables, such as age, sex, physical activity, and energy intake, this study still has some limitations. First, the present study is observational. Second, we used a recall 24-hour questionnaire to estimate calorie intake, meaning that information bias is probable. Third, this study had a small sample size, thus, the results cannot be generalized to a large population. Also, the dissimilarity in the number of participants in the two groups reduced their comparability. Fourth, some confounding variables, which may affect food intake, such as nutrient intake, educational level, occupation, and level of stress, were not considered.

\section{Conclusion}

Despite the evidence suggesting the effect of chronotype on food intake timing and obesity, this effect was not observed in the present study. Energy calculations were based on the participants' selfreports, which might have led to information bias. Therefore, clinical trials should be carried out in the future in which food intake is controlled by considering meal timing.

\section{Acknowledgments}

The authors appreciate the valuable assistance of all participants in the study.

\section{Conflict of Interest}

The authors declared no conflict of interest.

\section{References}

1. Sharma A. Obesity and cardiovascular risk. Growth Hormone \& IGF Research. J Growth Hormone Res Soc Int IGF Res Soc. 2003; Suppl A:S10-7. DOI: 10.1016/s1096-6374(03)00047-9.2003;13:S10-S7. [DOI:10.1016/S1096-6374(03)00047-9]

2. Guh DP, Zhang W, Bansback N, Amarsi Z, Birmingham CL, Anis AH. The incidence of comorbidities related to obesity and overweight: a systematic review and meta-analysis. BMC Public
Health. 2009;9(1):88. [DOI:10.1186/1471-2458-988]

3. Johnston $\mathrm{BC}$, Kanters $\mathrm{S}$, Bandayrel $\mathrm{K}$, et al. Comparison of weight loss among named diet programs in overweight and obese adults: a metaanalysis. JAMA. 2014;312(9):923-33. [DOI:10.1001/jama.2014.10397]

4. Ng SW, Zaghloul S, Ali H, Harrison G, Popkin BM. The prevalence and trends of overweight, obesity and nutrition-related non-communicable diseases in the Arabian Gulf States. Obesity Reviews. 2011;12(1):113. [DOI:10.1111/j.1467-789X.2010.00750.x]

5. Froy O. Metabolism and circadian rhythmsimplications for obesity. Endocrine Rev. 2010;31(1):1-24. [DOI:10.1210/er.2009-0014]

6. Marcheva B, Ramsey KM, Buhr ED, et al. Disruption of the clock components CLOCK and BMAL1 leads to hypoinsulinaemia and diabetes. Nature. 2010;466(7306):627-31. [DOI:10.1038/nature09253]

7. Oishi K, Shirai H, Ishida N. CLOCK is involved in the circadian transactivation of peroxisome-proliferatoractivated receptor $\alpha(\mathrm{PPAR} \alpha)$ in mice. Biochem J. 2005;386(3):575-81. [DOI:10.1042/BJ20041150]

8. Turek FW, Joshu C, Kohsaka A, et al. Obesity and metabolic syndrome in circadian Clock mutant mice. Science. [DOI:10.1126/science.1108750]

9. Arble DM, Bass J, Laposky AD, Vitaterna MH, Turek FW. Circadian timing of food intake contributes to weight gain. Obesity. 2009;17(11):2100-2. [DOI:10.1038/oby.2009.264]

10. Ross KM, Graham Thomas J, Wing RR. Successful weight loss maintenance associated with morning chronotype and better sleep quality. J Behav Med. 2016;39(3):465-71. [DOI:10.1007/s10865-015-97048]

11. Kandeger A, Selvi Y, Tanyer DK. The effects of individual circadian rhythm differences on insomnia, impulsivity, and food addiction. Eat Weight Disord. 2019;24(1):47-55. [DOI:10.1007/s40519-018-0518x]

12. Maukonen M, Kanerva N, Partonen T, Mannisto S. Chronotype and energy intake timing in relation to changes in anthropometrics: a 7-year follow-up study in adults. Chronobiol Int. 2019;36(1):27-41. [DOI:10.1080/07420528.2018.1515772]

13. Von Elm E, Altman DG, Egger $\mathrm{M}$, et al. The strengthening the reporting of observational studies in epidemiology (STROBE) statement: guidelines for reporting observational studies. PLoS medicine. 2007;4(10):e296.

[DOI:10.1371/journal.pmed.0040296]

14. Horne JA, Östberg O. A self-assessment questionnaire to determine morningness-eveningness in human circadian rhythms. Int J Chronobiol. 1976.4(2):97-110

15. Mozafari A, Tabaraie M, Tahrodi MHM. Morningness-eveningness chronotypes, insomnia and sleep quality among medical students of Qom. J Sleep Sciences. 2016;1(2):67-73. 
16. Rahmani A, Sayehmiri K, Asadollahi K, Sarokhani D, Islami F, Sarokhani M. Investigation of the prevalence of obesity in Iran: a systematic review and metaanalysis study. Acta Medica Iranica. 2015;53(10):596-607.

17. Muñoz J, Cañavate R, Hernández C, Cara-Salmerón $\mathrm{V}$, Morante J. The association among chronotype, timing of food intake and food preferences depends on body mass status. Eur J Clin Nutr. 2016;71(6):736-42. . [DOI:10.1038/ejen.2016.182]

18. Reid KJ, Baron KG, Zee PC. Meal timing influences daily caloric intake in healthy adults. Nutr Res. 2014;34(11):930-5.

[DOI:10.1016/j.nutres.2014.09.010]

19. Hermengildo Y, López-García E, García-Esquinas E, Pérez-Tasigchana RF, Rodríguez-Artalejo F, GuallarCastillón P. Distribution of energy intake throughout the day and weight gain: a population-based cohort study in Spain. Br J Nutr. 2016;115(11):2003-10. [DOI:10.1017/S0007114516000891]

20. Wang J, Patterson R, Ang A, Emond J, Shetty N, Arab L. Timing of energy intake during the day is associated with the risk of obesity in adults. J Human Nut Diet. 2014;27(s2):255-62 [DOI:10.1111/jhn.12141]

21. de Castro JM. The time of day of food intake influences overall intake in humans. J Nutr. 2004;134(1):104-11. [DOI:10.1093/jn/134.1.104]

22. Gonnissen $H$, Hulshof $T$, Westerterp-Plantenga $M$. Chronobiology, endocrinology, and energy-and foodreward homeostasis. Obesit Rev. 2013;14(5):405-16. [DOI:10.1111/obr.12019]

23. Froy O. The relationship between nutrition and circadian rhythms in mammals. Front Neuroendocrinol. 2007;28(2):61-71. [DOI:10.1016/j.yfrne.2007.03.001]

24. Reppert SM, Weaver DR. Coordination of circadian timing in mammals. Nature. 2002;418(6901):935-41. [DOI: 10.1038/nature00965]

25. Garaulet M, Ordovas JM, Madrid JA. The chronobiology, etiology and pathophysiology of obesity. Int J Obesit. 2010;34(12):1667-83. [DOI:10.1038/ijo.2010.118]

26. Lamont EW, Harbour VL, Barry-Shaw J, et al Restricted access to food, but not sucrose, saccharine, or salt, synchronizes the expression of Period2 protein in the limbic forebrain. Neuroscience. 2007;144(2):402-11.

[DOI:10.1016/j.neuroscience.2006.09.027]

27. Lowrey PL, Takahashi JS. Mammalian circadian biology: elucidating genome-wide levels of temporal organization. Annu Rev Genomics Hum Genet. 2004;5:407-41.

[DOI:10.1146/annurev.genom.5.061903.175925]

28. Garaulet M, Gómez-Abellán P. Timing of food intake and obesity: a novel association. Physiol Behav. 2014;134:44-50.

[DOI:10.1016/j.physbeh.2014.01.001]

29. Gómez-Abellán P, Madrid JA, Ordovás JM, Garaulet M. Chronobiological aspects of obesity and metabolic syndrome. Endocrinol Nut. 2012;59(1):50-61. [DOI:10.1016/j.endonu.2011.08.002]

30. Garaulet M, Ordovás JM, Gómez-Abellán P, Martínez JA, Madrid JA. An approximation to the temporal order in endogenous circadian rhythms of genes implicated in human adipose tissue metabolism. J Cell Physiol. 2011;226(8):2075-80. [DOI:10.1002/jicp.22531]

31. Loboda A, Kraft WK, Fine B, et al. Diurnal variation of the human adipose transcriptome and the link to metabolic disease. BMC Med Genomics. 2009;2(1):7. [DOI:10.1186/1755-8794-2-7]

32. Ptitsyn AA, Zvonic S, Conrad SA, Scott LK, Mynatt RL, Gimble JM. Circadian clocks are resounding in peripheral tissues. PLoS Comput Biol. 2006;2(3):e16. [DOI:10.1371/journal.pcbi.0020016]

33. Tu BP, Kudlicki A, Rowicka M, McKnight SL. Logic of the yeast metabolic cycle: temporal compartmentalization of cellular processes. Science. 2005;310(5751):1152-8. [DOI:10.1126/science.1120499]

34. Ruiz-Lozano T, Vidal J, de Hollanda A, Canteras M, Garaulet M, Izquierdo-Pulido M. Evening chronotype associates with obesity in severely obese subjects: interaction with CLOCK 3111T/C. Int J Obes .2016 ;40(10):1550-7. [DOI:10.1038/ijo.2016.116]

35. Maukonen $\mathrm{M}$, Kanerva $\mathrm{N}$, Partonen $\mathrm{T}$, et al. Chronotype differences in timing of energy and macronutrient intakes: A population-based study in adults. Obesity .2017;25(3):608-15. [DOI:10.1002/oby.21747]

\section{How to Cite This Article:}

Yazdinezhad A, Askarpoor M, Aboushamsia M, Asadi M, Mansoori A. Evaluating the Effect of Chronotype on Meal Timing and Obesity in Iranian Housewives: A Cross-Sectional Study. J Adv Med Biomed Res. 2019; 27 (124): $31-36$

\section{Download citation:

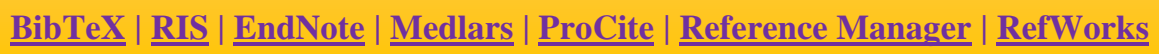

\section{Send citation to:

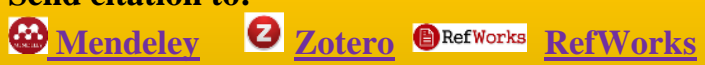

